\title{
Ulnar nerve entrapment neuropathy at the elbow: decisional algorithm and surgical
} considerations

\author{
C. Mandelli and M. Baiguini
}

Department of Neurosurgery. IRCCS San Raffaele. Milano. Italy.

\section{Summary}

Introduction. We propose our surgical experience and the decisional algorithm we use to select the surgical procedure for the ulnar nerve entrapment at the elbow according to defined parameters.

Materials and methods. Between 2005 and 2007, 44 patients were operated according to our algorithm that is based both on clinical parameters, classified through the McGowan scale, and on biological ones (the nervous morphology and the amount of scar around the medial epicondyle). Patients were treated through "modified" in situ simple decompression, subcutaneous and sub muscular transpositions.

Results. After an average follow-up of 13.4 months, function improved by one grade in $70 \%$ of patients, two grades in $16 \%$ and there was no change in $14 \%$. Moreover $84,8 \%$ of patients operated through the modified in situ decompression technique reported an excellent outcome.

Conclusion. We suggest an algorithm for uniformly treat the patients with cubital tunnel syndrome through a clinical and biological point of view. The modified in situ decompression is a safe and effective treatment for the majority of these patients reducing the risk of redo surgery.

KEY WORDS: Anterior transposition. Simple neurolysis. Ulnar nerve. Cubital tunnel syndrome.

Neuropatía por atrapamiento del nervio ulnar en el codo: procedimiento decisivo y consideraciones quirúrgicas

\section{Resumen}

Introducción. Proponemos nuestra experiencia quirúrgica y el método decisivo que utilizamos para elegir la técnica quirúrgica en el atrapamiento del nervio

Recibido: 10-04-08. Aceptado: 20-05-08 ulnar en el codo según parámetros concretos.

Materiales y técnicas. Entre el 2005 y el 2007, 44 pacientes han sido sometidos a cirugía según nuestro algoritmo basado en unos parámetros clínicos, clasificados a través de la escala de McGrowan, y otros biológicos ( morfología del nervio y cantidad de cicatriz en torno al epicóndilo medial). Los pacientes fueron tratados mediante la decompresión simple "modificada" in situ, la transposición subcutánea y submuscular.

Resultados. Después de un control durante 13.4 meses, el $70 \%$ recuperó la función en un grado, el $16 \%$ en dos grados y no hubo cambios en el $14 \%$.

Además, el $84,8 \%$ de los pacientes operados mediante la técnica de decompresión modificada in situ presentó excelentes resultados.

Conclusión. Proponemos un algoritmo para tratar uniformemente pacientes con síndrome del túnel cubital a través de puntos de vista clínicos y biológicos. La decompresión modificada in situ es un tratamiento seguro y eficaz en la mayor parte de pacientes reduciendo el riesgo de reintervención.

PALABRAS CLAVE: Transposición anterior. Neurolisis simple. Nervio ulnar. Síndrome del túnel cubital.

\section{Introduction}

Ulnar nerve entrapment at elbow is considered the second most common compression neuropathy of the upper limb after carpal tunnel syndrome ${ }^{4}$.

With the normal motion of the elbow, the ulnar nerve is subjected to frictional injuries and compression can occur in 5 anatomic points ${ }^{4,6}$ : the arcade of Struthers ${ }^{14}$, a second site just proximal to the medial epicondyle, the ulnar groove, the point between the humeral and ulnar heads of the flexor carpi ulnaris muscle and, finally, where the ulnar nerve leaves the flexor carpi ulnaris. According to different studies, the ulnar nerve is much more vulnerable to compression through the previous third and fourth anatomic regions 5 .

The diagnosis of cubital tunnel syndrome is made 
Table 1

\section{Decisional surgical algorithm}

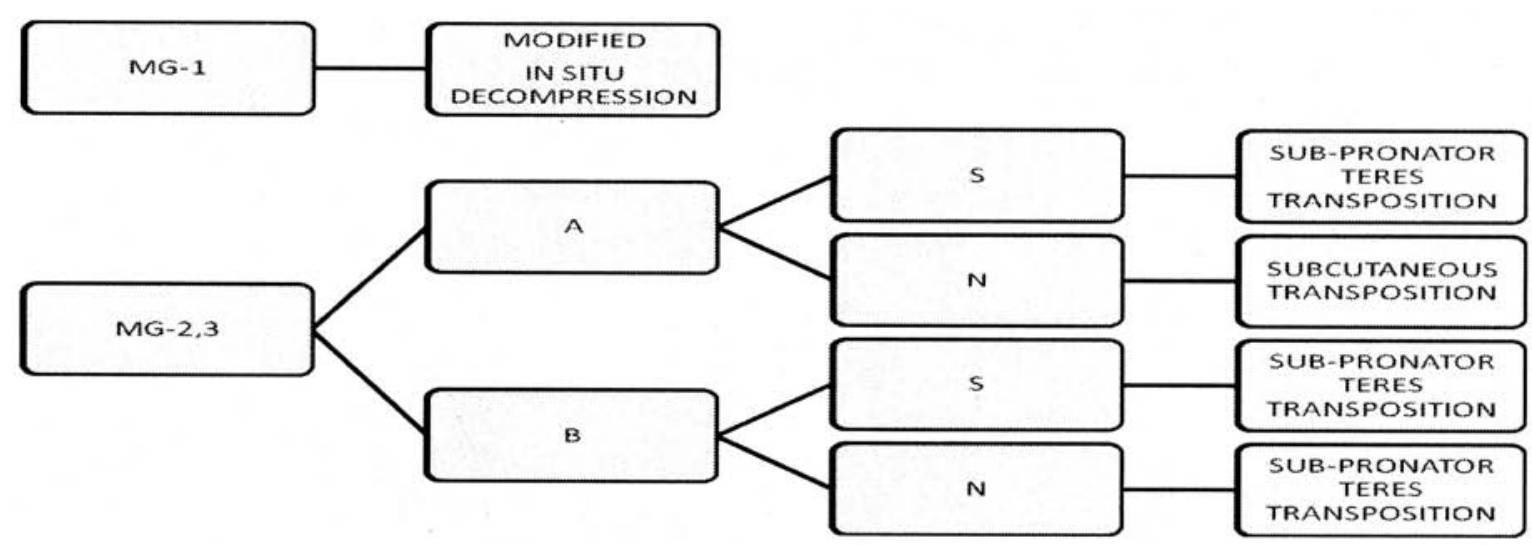

MG: McGowan Scale

A. Nervous morphology: no anomalous curvature, no or mild calliper variation, no or mild colour anomalies. B. Nervous morphology: anomalous curvature, evident calliper variation, colour anomalies. S. Tissues around the medial epicondyle: presence of a large amount of scar. N. Tissues around the medial epicondyle: no or mild presence of scar. Note: sub-muscular transposition is avoided in patients with cicatrization problems or severe vasculopathy (diabetics....)

by a combination of patient symptoms, history, physical examination and electrodiagnostic studies. Clinical and electromyographic findings provide critical pre-operative information.

Initial treatment of the syndrome is conservative ${ }^{6}$. If this is unsuccessful or neurologic deficits are present the surgical option is considered. The following techniques of decompression are reported in literature ${ }^{1,4,8,11-13,15}$ : simple decompression (neurolysis), subcutaneous/intramuscular/ sub-muscular transpositions, subtotal medial epicondylectomy.

We have not found in literature a unanimous consensus that could help the surgeon in the choice of the appropriate surgical procedure according to defined parameters. The aim of our article is to propose our surgical experience and the algorithm we use to select a surgical option or the other one.

A new surgical technique of simple in situ decompression at the elbow is also reported.

\section{Materials and methods}

Between 2005 and 2007, 44 consecutive patients with ulnar neuropathy were operated on in our Neurosurgical Department by C.M. according to a specific decisional algorithm (table 1).

Thirty four patients were males and 10 were females, ranging in age from 20 to 81 (mean, 47 years).
The patients were clinically divided into three groups according to the McGowan scale ${ }^{4,10}$. Group 1 includes those patients with irritative manifestations in the ulnar nerve distribution without muscle weakness. Group 2 refers to cases with muscle atrophy on physical examination, a decrease of intrinsic muscle function and abnormal 2-point discrimination. Group 3 implies severe paralysis of the intrinsic muscles, profound sensory changes and possible claw-hand.

All the patients underwent an electromyographic examination to support the previous clinical findings.

The radiographic examination of the elbow was performed only in posttraumatic patients. The patients in Group 1 were treated conservatively for three months and, if no improvement of the symptoms was observed, referred to surgery. The surgical procedure proposed to these patients was the decompression in situ as recommended in the literature $^{11-13}$ considering that the ulnar nerve is more vulnerable to compression at the groove and between the humeral and ulnar heads of the flexor carpi ulnaris.

Our surgical technique implies an external neurolysis and the dissection of the subcutaneous fat that is placed under the nerve (Fig. 1).

The details of the modified in situ decompression are reported:

The patient is positioned supine with the arm abducted and externally rotated and the elbow flexed to about $60^{\circ}$. Local anaesthesia with Lydocaine is injected. 


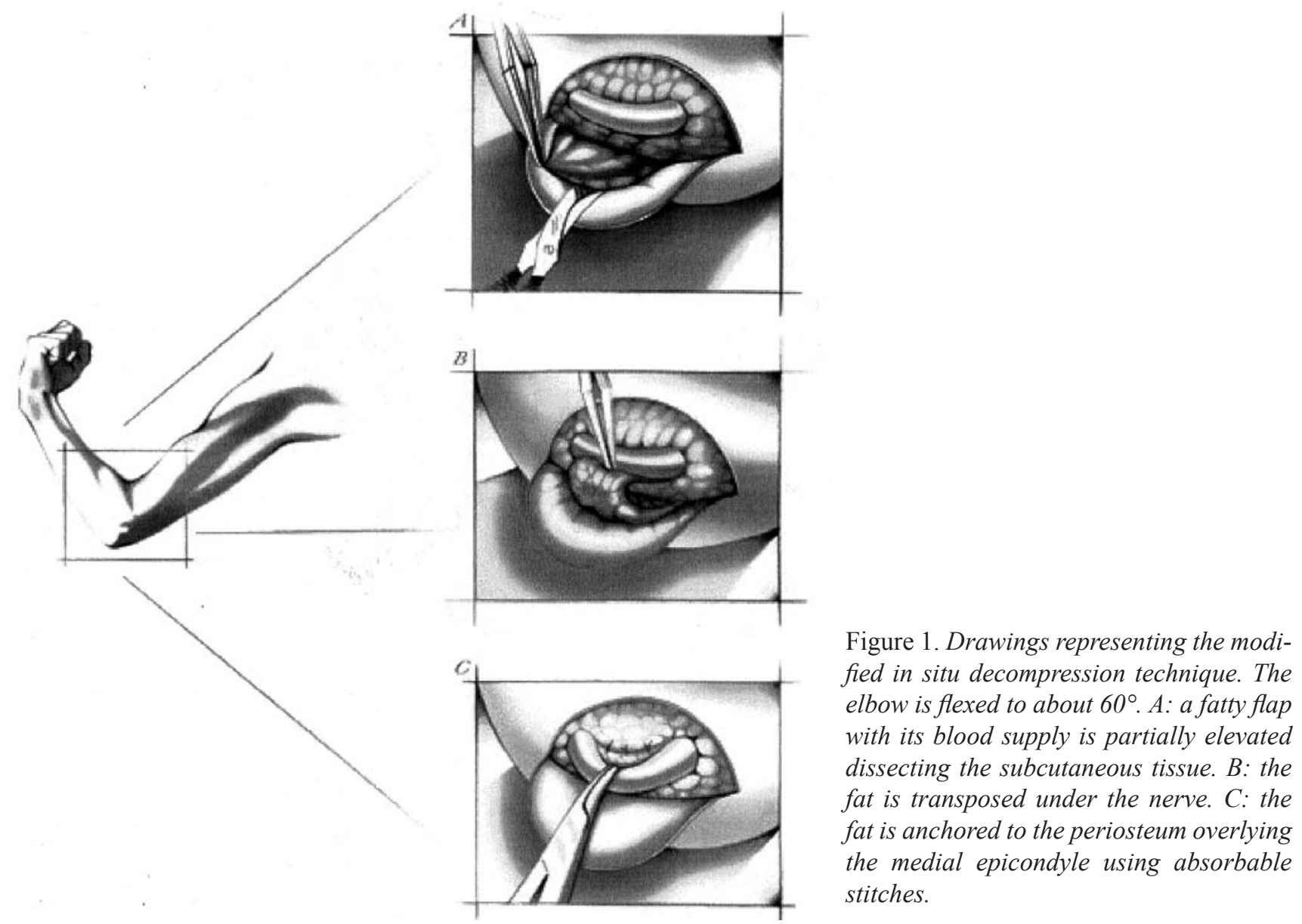

In our practice we do not use plexic anaesthesia and tourniquet control.

The nerve is palpated just medially to the humeral epicondyle and a 6-8 cm curvilinear incision is extended around the epicondyle tip.

The skin flap is mobilized and the cutaneous nervous branches are preserved and retracted whenever possible.

The muscular fascia is exposed and incised along the course of the nerve.

The nerve is identified in its groove and distally followed widening of its entrance to the cubital tunnel and dividing the Osborne ligament. The external neurolysis is also

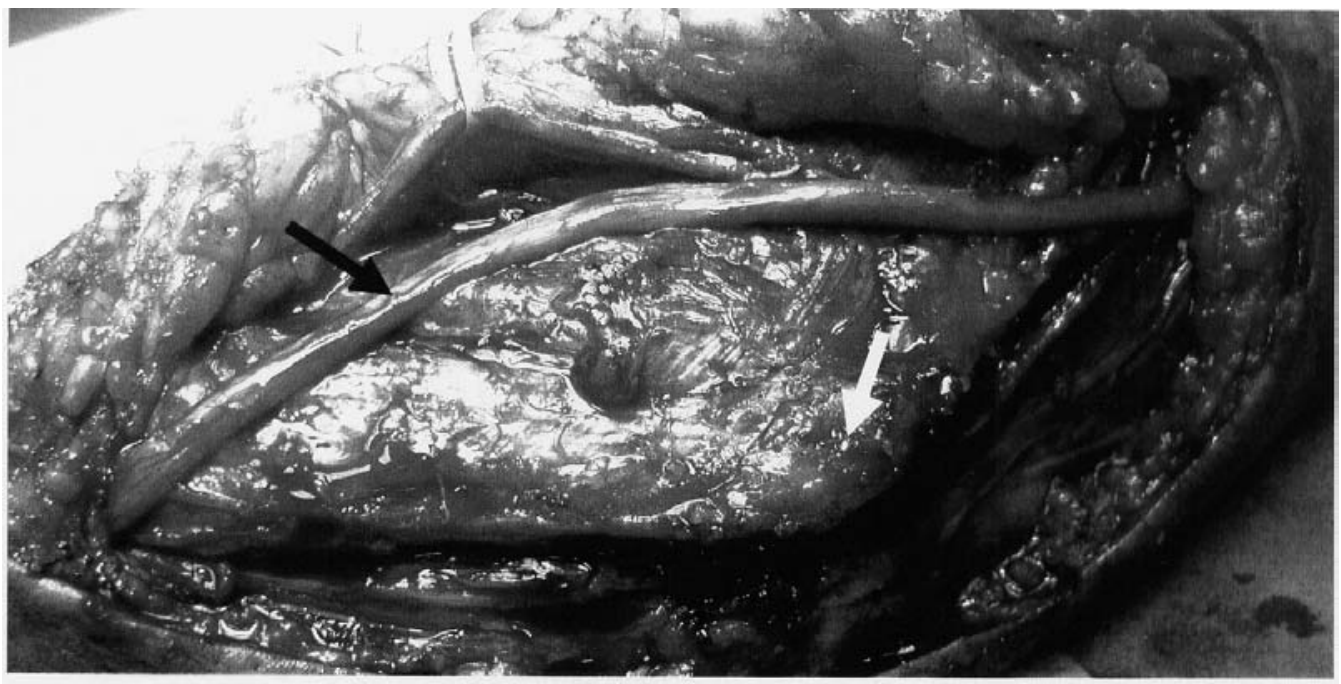

Figure 2. Intraoperative morphology of a right ulnar nerve that is transposed in a subcutaneous location (black arrow). No scar tissue is present around the medial epicondyle (white arrow). 


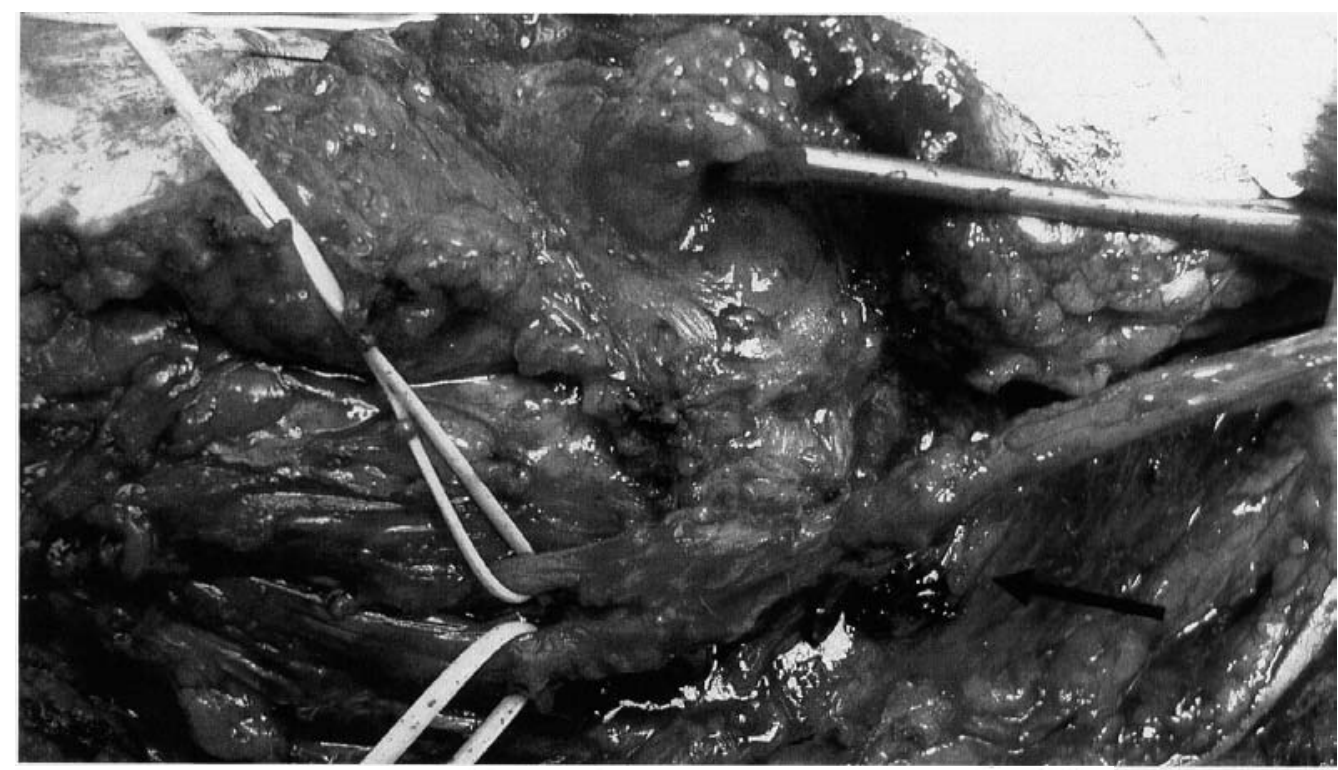

Figure 3. Intraoperative view of a right ulnar nerve that will be transposed under the muscle. Note the altered nervous morphology and the high amount of scar around the medial epicondyle (black arrow)

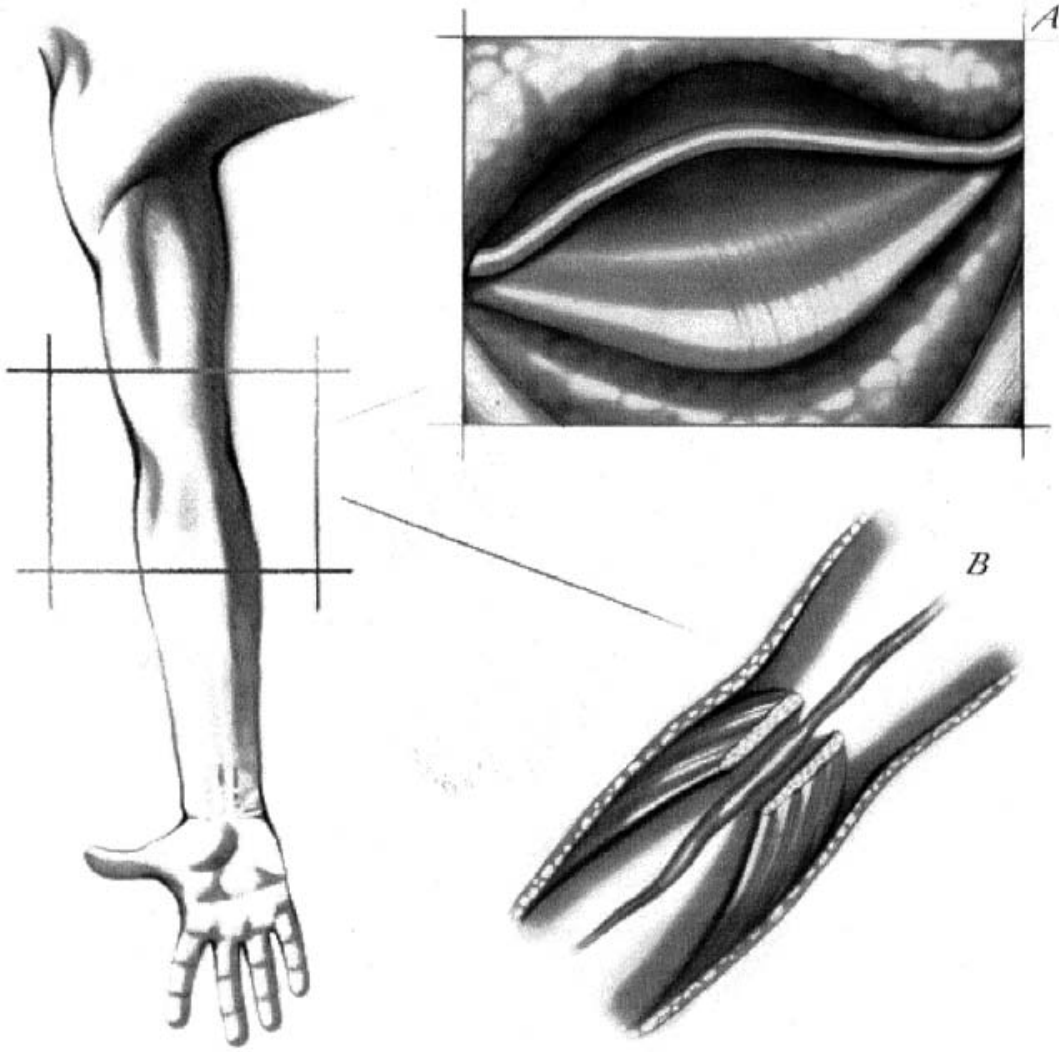

Figure 4. Drawings representing the transpositional techniques and the tissutal parameters. The elbow is extended. A: the ulnar nerve with a preserved elasticity (no anomalous curvature, no or mild calliper variation, no or mild colour anomalies) is transposed in a subcutaneous location. There is no or mild scar tissue around the medial epicondyle. B: The ulnar nerve with an altered morphology is placed under the pronator teres muscle.

proximally completed in order to reach a final mobilization of the nerve.

An accurate haemostasis is acquired through bipolar cautery avoiding whenever possible damages to the nervous vascular bundle ${ }^{11}$.

A fatty flap with its blood supply is partially elevated dissecting the subcutaneous tissue. The fat is transposed under the nerve and anchored to the periosteum overlying the medial epicondyle using 4-0 absorbable stitches.
We take care that the fatty section attached to the subcutaneous tissue doesn't produce a cutaneous fold after the previous procedure because of its stretching.

The aim of this technique is to create a soft "bed" under the nerve.

A final checking ensures that there is no tension or kinking of the nerve during the flexion and extension of the arm.

The entire course of the ulnar nerve exposed is inspec- 
ted to exclude any residual compression.

The wound is closed using 3-0 interrupted Vicryl suture for the subcutaneous layer and subcuticular 4-0 absorbable suture for the skin.

Patients in Groups 2 and 3 are referred to surgery which implies subcutaneous or sub-muscular nerve transposition.

The appropriate procedure is selected considering the following tissutal parameters that are detected during surgery: the nervous elasticity and the amount of scar in the surrounding tissues around the medial epicondyle.

The nervous elasticity is classified according to the nervous aspect and morphology:

A: no anomalous curvature, no or mild calliper variation, no or mild colour anomalies.

B: anomalous curvature, evident calliper variation, colour anomalies.

The amount of scar in the surrounding tissues around the medial epicondyle is also classified into two categories:

$\mathrm{S}$ : tissues with presence of a large amount of scar.

$\mathrm{N}$ : tissues with no or mild presence of scar.

Patients in McGowan Groups 2 and 3 with a nervous aspect classified as A (Fig. 2). are referred to subcutaneous transposition. On the other hand nerves with a $\mathrm{B}$ aspect (Fig. 3) are placed under the pronator teres muscle (Fig. 4).

In all the situations (A and B), if it is present a large amount of scar around the medial epicondyle $(\mathrm{S})$, the nerve is placed under the muscle. If no or mild scar tissue is evident $(\mathrm{N})$, the nerve is placed in the subcutaneous or sub-muscular location according to A or B category (Table 1 and Fig. 1-4).

Besides we prefer to perform a sub muscular transposition in cases of important neuropathic pain independently by the nerve morphology and surrounding tissue aspect.

On the other hand we usually avoid the sub muscular transposition in patients with cicatrisation problems or severe vasculopathy (diabetics...).

\section{Results}

Forty-four patients with ulnar nerve entrapment at the elbow were evaluated. Symptoms were present more than 3 months. According to McGowan scale, 28 patients were in Grade 1, 7 in Grade 2 and 9 in Grade 3.

At operation $32(72.2 \%)$ patients were noted to have an ulnar nerve morphology classified as A and $12(27,8 \%)$ as B.

The amount of scar was in Class S for $11(25 \%)$ patients and in Class $\mathrm{N}$ for $33(75 \%)$ patients.

According to our decisional algorithm, 63.6\% of patients underwent the modified in situ decompression, $6.8 \%$ the subcutaneous transposition and $29.5 \%$ the sub muscular transposition.

Clinical follow-up examination was performed in all the patients 4 to 21 months postoperatively with a mean of 13.4 months and reclassified according to the McGowan scale.

No operative complications occurred. Besides we did not experience postoperative problems linked to the surgical wounds or soft tissues after each of the considered techniques.

Postoperatively $63,6 \%$ patients presented an excellent outcome with both sensory and motor restitution (nearly normal situation with sporadic paresthesia). On the other hand $27,4 \%$ of patients was graded as McGowan 1, 5,5\% as McGowan 2 and 4,5\% as McGowan 3.

Results based on a more detailed evaluation showed that the $84,8 \%$ patients operated on through the modified in situ decompression technique experienced the excellent outcome and 15,2\% remained in McGowan 1 . These results were not linked to the possible presence of subluxation of the ulnar nerve over the medial epicondyle.

Among the patients that performed the subcutaneous transposition, 33,3\% had an excellent outcome, 66.7\% were in McGowan 1 and $0 \%$ in McGowan 2. Among these patients, two were previously operated on through our modified in situ decompression technique.

Finally, after the sub muscular transposition, 7.6\% reached the excellent outcome, $61.5 \%$ improved to McGowan 1, 15.3\% to McGowan 2 and $15.6 \%$ presented a McGowan 3.

Results are summarized in Tables 2A and 2B.

Preoperative factors like age or concomitant diseases did not influenced significantly the overall outcome or the decision making toward one technique or the other. Anyway we do not usually perform the sub-muscular transposition in patients with potential cicatrisation problems or severe vasculopathy.

\section{Discussion}

Various surgical procedures have been described for the treatment of cubital tunnel syndrome. Many studies focus on the evolution of surgically treated patients but we have observed that there is not a unanimous consensus regarding the choice of the appropriate surgical procedure according to defined parameters.

In other words, from the Literature, we know the results of the different surgical techniques and what we can expect from a surgical therapy but we do not know the objective indications of each single procedure.

In spite of these limitations we have proposed a decisional algorithm that could help the surgeon in the choice of the appropriate technique. The algorithm is based both on clinical parameters classified through the McGowan scale, 
Table 2 A

Grades of McGowan improvement for each surgical technique

\begin{tabular}{|c|c|c|c|c|}
\hline \multirow[b]{2}{*}{$\begin{array}{l}\text { Grades of improvement in } \\
\text { the MG scale }\end{array}$} & \multicolumn{3}{|c|}{ Surgical technique } & \multirow[b]{2}{*}{ Total } \\
\hline & $\begin{array}{l}\text { Modified in situ } \\
\text { decompression }\end{array}$ & $\begin{array}{l}\text { Subcutaneous } \\
\text { transposition }\end{array}$ & $\begin{array}{l}\text { Sub-muscular } \\
\text { transposition }\end{array}$ & \\
\hline-2 & $0 \%$ & $67 \%$ & $38 \%$ & $16 \%$ \\
\hline-1 & $86 \%$ & $33 \%$ & $46 \%$ & $70 \%$ \\
\hline 0 & $14 \%$ & $0 \%$ & $15 \%$ & $14 \%$ \\
\hline
\end{tabular}

MG: McGowan

Table 2 B

Grades oimprovement $i$ the McGowan scale following the decisional algorithm

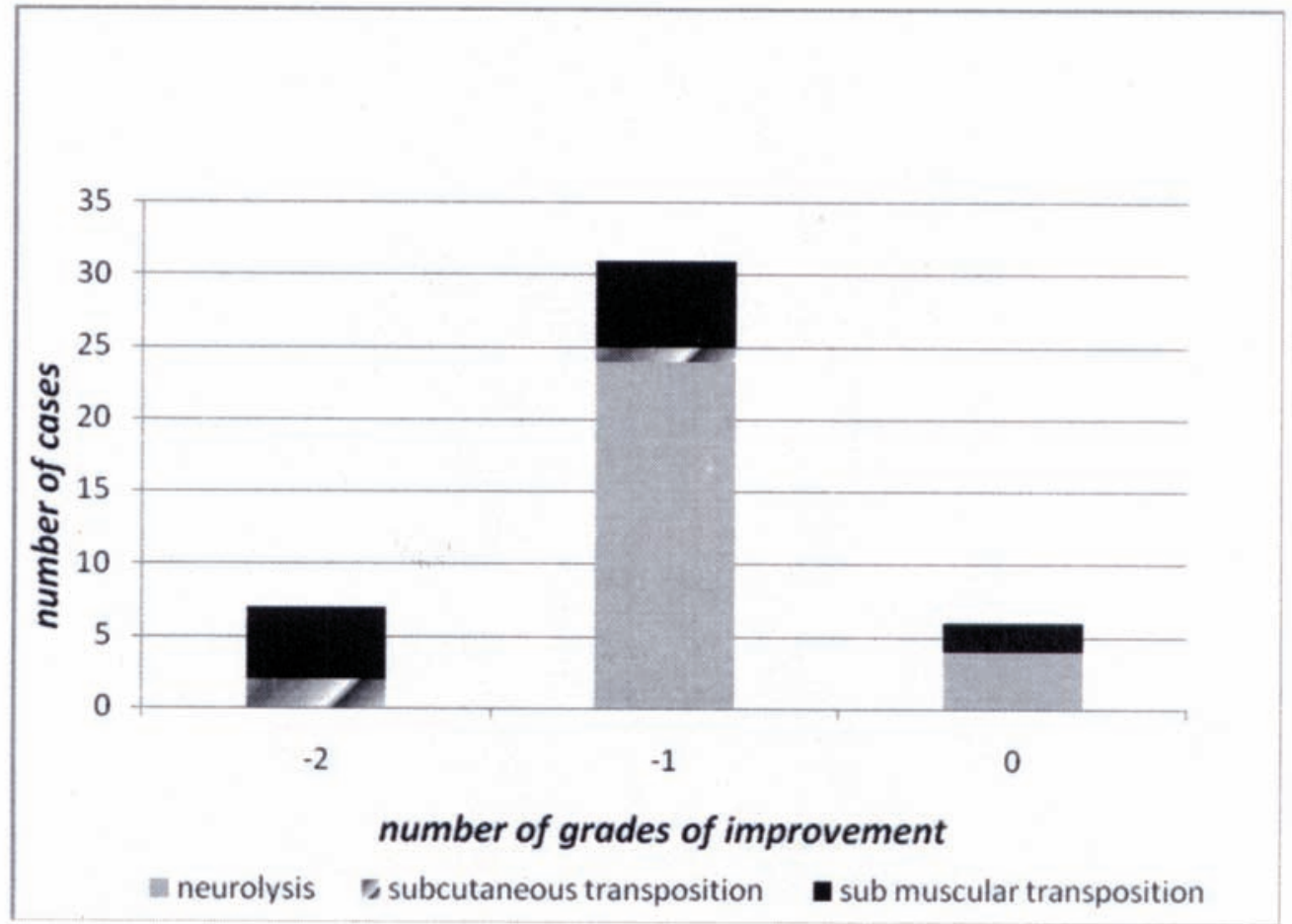

and on biological ones that are represented by the nervous morphology, mirroring the degree of its fibrous invasion, and the amount of scar that reflects the condition of the surrounding tissues.

It is possible that patients with an irritative history may have less intraneural fibrosis and would thus be more likely to respond to surgery. These patients are usually operated on through a simple decompression at the elbow according to the points of major ulnar nerve compression at this level. In these cases the nerve usually preserves its elasticity and the surrounding tissues remains favourable to regeneration after nervous neurolysis. The simple decompression allows patients to avoid elbow instability and assess good decompression of the nerve using a simple and less invasive technique $^{12}$.

We have modified the standard technique of in situ decompression in order to create a peduncolated soft bed for the decompressed nerve excluding its contact with the bony structures. In fact it is our opinion that, despite decompression, an ulnar nerve that remains in strict contact with the groove after surgery, continues to move inside it after flexion of the elbow compromising its intraneural 
circulation and with the result of fibroblastic invasion and possible persistence or recurrence of the symptomathology9.

Besides our technique is valuable also in cases of nervous subluxation around the medial epicondyle because the nerve moves over a flat and soft surface. It is important that the fatty thickness placed under the nerve should not create a lever effect after elbow flexion. This is the reason to carefully inspect the nervous movements and decompression during elbow flexion performed while operating the patient. Another technical point linked to this technique is the surgical incision. We perform a curvilinear incision that implies a subcutaneous dissection to reach the ulnar groove. During this dissection it is mandatory the cutaneous branches sparing in order to avoid postoperative neuronal and local pain.

Patients with McGowan 2 and 3 were referred to transposition surgery. In these cases we also considered the biological factors in the decision making: nervous morphology and scar. Kleinman demonstrated that anterior transposition is a logical approach to complete nerve decompression ${ }^{7}$. The presence of fibrosis and adhesions adversely affects the outcome $e^{3}$ and this is the reason we usually place under the muscle the ulnar nerve in cases of large amount of scar extending around the medial epicondyle. The transposed ulnar nerve in a stable environment represents a good solution to protect the nerve itself also in cases, defined as B, of neural fibrous invasion (assonotmetic damages). We therefore exclude the internal neurolysis as suggested by Broudy ${ }^{2}$ and perform the external neurolysis releasing all sites of compression distally and proximally placing the nerve in an appropriate biological area for regeneration. The sub-muscular transposition has also the advantages to place the nerve over an anatomic plane that is at the same level of the ulnar nerve branches entering into the flexor carpi ulnaris. This condition avoids in hypo elastic nerves additional nervous kinking linked to the altered trajectory through different anatomic planes as in the subcutaneous transposition.

Following our decisional algorithm, after an average follow-up of 26.4 months (range, 4 to 41 months), function improved by one grade in $70 \%$ of patients, two grades in $16 \%$ and there was no change in $14 \%$. A more specific analysis showed that $84,8 \%$ patients operated on through the modified in situ decompression technique reported an excellent outcome.

According to our follow-up, the duration of symptoms appears to correlate with outcome moreover in patients classified as McGowan 1. In fact it is our feeling that they should be operated on as soon as possible after three months of clinical observation if persistent symptoms are present.

\section{Conclusion}

Although our small number of patients treated through a specific decisional algorithm does not allow us to draw general conclusions, we think our report make a contribution suggesting a decisional scheme that could help the surgeon to uniformly treat the patients with cubital tunnel syndrome through a clinical and biological point of view. The modified in situ decompression technique is a safe and effective treatment for the majority of patients affected by cubital tunnel syndrome reducing the risk of redo surgery.

\section{References}

1. Adson, A.W.: The surgical treatment of progressive ulnar paralysis. Minn Med 1918; 1: 455-460.

2. Broudy, A.S., Leffert, R.D., Smith, R.J.: Technical problems with ulnar nerve transposition at the elbow: findings and results of reoperation. J. Hand Surg. 1978; 3: 85-89.

3. Dagregorio, G., Saint-Cast, Y.: Simple neurolysis for failed anterior submuscolar transposition of the ulnar nerve at the elbow. Intern Orthop (SICOT) 2004; 28: 342-346.

4. Dinh, P.T., Gupta, R.: Subtotal medial epicondylectomy as a surgical option for treatment of cubital tunnel syndrome. Tech Hand Up Extrem Surg. 2005; 9: 52-59.

5. Feindel, W., Stratford, J.: The role of the cubital tunnel in tardy ulnar palsy. Can. J. Surg. 1958; 1: 287-300.

6. Kim, D.H., Han, K., Tiel, R.L., Murovic, J.A., Kline, D.G.: Surgical outcomes of 654 ulnar nerve lesions. J. Neurosurg. 2003; 98: 993-1004.

7. Kleinman, W.B.: Cubital tunnel syndrome: anterior transposition as a logical approach to complete nerve decompression. J. Hand Surg. [Am] 1999; 24: 886-897.

8. Kline, D.G., Hudson, A.R., Kim, D.H.: Ulnar nerve. Atlas of peripheral nerve surgery. Saunders Company (ed). 2001: pp. 77-83.

9. LeRoux, P.D., Ensign, T.D., Burchiel, K.J.: Surgical decompression without transposition for ulnar neuropathy: factors determining outcome. Neurosurgery 1990; 27: 709714

10. McGowan, A.J.: The results of transposition of the ulnar nerve for traumatic ulnar neuritis. J. Bone Jt. Surg. 1950; 32B: 293-301.

11. Messina, A., Messina, J.C.: Transposition of the ulnar nerve and its vascular bundle for the entrapment syndrome at the elbow. J. Hand Surg. 1995; 20B: 5: 638-648.

12. Nathan, P.A., Keniston, R.C., Meadows, K.D.: Outcome study of ulnar nerve compression at the elbow treated with simple decompression and an early programme of physical therapy. J. Hand Surg. [British and European ] 1995; 20B: 5: 628-637.

13. Nathan, P.A., Istvan, J.A., Meadows, K.D.: Intermediate and long-term outcomes following simple decompression of the ulnar nerve at the elbow. Chir de la Main 2005; 24: 29-34.

14. Nathan, P., Myers, L.D., Keniston, R.C., Meadows, 
K.D.: Simple decompression of the ulnar nerve: an alternative to anterior transposition. J. Hand Surg.[Br] 1992; 17B: 251-254.

15. Richmond, J.C., Southmayd, W.: Superficial anterior transposition of the ulnar nerve at the elbow for ulnar neuritis. Clin Orthop Related Res 1982; 164: 42-44.

16. Spinner, M., Kaplan, E.B.: The relationship of the ulnar nerve to the medial intermuscular septum in the arm and its clinical significance. Hand 1976; 16: 239-242.

17. Spinner, M., Spencer, P.S.: Nerve compression lesions of the upper extremity. Clin Orthop 1974; 104: 46-47.

Mandelli, C.; Baiguini, M.: Ulnar nerve entrapment neuropathy at the elbow: decisional algorithm and surgical considerations. Neurocirugía 2009; 20: 31-38.

Corresponding author: Carlo Mandelli MD Divisione di Neurochirurgia IRCCS San Raffaele. Via Olgettina 60. 20132 Milano. Italy. 